\title{
Report
}

\section{Rose and in-vitro Inhibition of Sars-CoV-2 spike: ACE-2 interaction}

Mark Christopher Arokiaraj, ${ }^{*}$ Eric Menesson.\#

*Cardiology, Pondicherry Institute of Medical Sciences

India.

christomark@gmail.com

\#Tebu Bio, France.

Keywords: SARS-Cov-2 Spike protein: ACE2 inhibition, Rose extract, Covid-19.

\begin{abstract}
The study was performed to evaluate the novel potentials of red rose extract to inhibit SARS-CoV2 spike protein-Ace2 receptor interaction in vitro. ACE2 receptors were His-labelled, and the interaction was studied by chemiluminescence after the addition of anti-His HRP and HRP substrate. The inhibition of SARS-CoV-2 and ACE2 was seen in a dose-dependent sequence. The $50 \%$ inhibitory concentration was observed at 0.75 percent $\mathrm{v} / \mathrm{v}$ of the rose extract, and the $90 \%$ inhibition was seen at about 1.8 percent v/v. Steam inhalation or nebulization could be simple methods of delivering rose extract to the lower respiratory tract and pulmonary tissues. There is a potential for the rose extract to inhibit SARS-CoV-2 and ACE2 receptor inhibition in-vitro, which could have beneficial effects in Covid-19 treatment. Further tests need to be performed to study the therapeutic benefits in vivo.
\end{abstract}




\section{Introduction}

The pandemic by SARS-CoV-2 is evolving rapidly all over the world. The receptor binding sites of the SARS-Cov-2 viruses attach to ACE2 receptors on the surface of alveolar cells, endothelial cells, type 1 and 2 pneumocytes, and ciliated bronchial epithelial cells.1 After that, the viral replicates, and it is released from these cells. In this process, the cells are damaged and a significant inflammatory response is seen in these cells and the surrounding tissues. Currently, the spike protein is a common target for vaccine or SARS-CoV-2 Inhibitor development.2 The spike protein is also the commonest site for mutations which is an evasive mechanism due to natural selection pressure on the coronaviruses.3 Tropism to the respiratory tract of these viruses is well established, and in severe cases secondary viremia results. After that, immune mediated response to SARSCoV-2 further stimulate the pathological changes.1

In our previous study, we have shown that the rose extract has significant anti-inflammatory actions on the endothelial cells in-vitro.4 Endothelialitis and inflammation are the pathophysiological mechanisms for Sars-CoV-2 infections. Neo-intussusceptive type of angiogenesis, endothelial cell damage, microangiopathy, pulmonary alveolar cell injuries are commonly seen in Covid-19's acute respiratory distress syndrome (ARDS).5 Diffuse alveolar damage with micro or macro thrombosis are pathognomonic features. 6 Interestingly the pathologic observations of almost similar severity are also seen in influenza (H1N1) infections.5 Inhibition of the interaction between the spike protein of SARS-CoV-2 and ACE-2 could offer some protection against the viral infection. The study was performed in search of a novel inhibitory method for Sars-CoV-2 viruses, and thereby possibly reduce the morbidity and mortality of Covid-19.

\section{Methods}

The red rose extract was prepared by the standard method.4 The SARS-CoV-2 Spike: ACE2 Inhibitor Screening Assay Kit (BPS bioscience) was used for screening and rose extracts' possible role of inhibition of this interaction. The kit has a high sensitivity of detection of bound His-labelled ACE2 by HRP-labelled Anti-His.7,8 The rose extract was serially diluted in the test wells from 20 percent $\mathrm{v} / \mathrm{v}$ to 0.006 percent $\mathrm{v} / \mathrm{v}$.

\section{Coating the plate with SARS-CoV-2 Spike}

The plate was coated with $50 \mu \mathrm{l}$ SARS-CoV-2 Spike at $1 \mu \mathrm{g} / \mathrm{ml}$ in PBS for an overnight incubation at $4^{\circ} \mathrm{C}$. The plate was washed three times with $100 \mu \mathrm{l}$ x Immuno Buffer. The wells were blocked 
by adding $100 \mu \mathrm{l}$ of blocking buffer 2 to each well and incubated for $1 \mathrm{~h}$ at room temperature with slow shaking. The plate was washed three times with $100 \mu \mathrm{l}$ x Immuno buffer.

\section{Inhibition of binding}

$20 \mu \mathrm{l}$ of $1 \mathrm{x}$ Immuno buffer 1 were added to each well or $40 \mu \mathrm{l}$ for blank wells. $10 \mu \mathrm{l}$ of inhibitor solution were added to each well designated for compound testing. For the positive control and blank wells, $10 \mu \mathrm{l}$ of $5 \%$ solvent in water (inhibitor buffer) were added. The plate was incubated at room temperature for $1 \mathrm{~h}$ with slow shaking. If the compound solvent is DMSO or ethanol, the final solvent concentration in the assay should be $\leq 1 \%$ for compound testing, positive control and blank wells. Different reagents and compounds were distributed as indicated in the table 1.

ACE2-His was diluted to $2.5 \mathrm{ng} / \mu 1$ (approximately $30 \mathrm{nM}$ ) in $1 \mathrm{x}$ Immuno buffer 1 . The reaction was initiated by adding $20 \mu \mathrm{l}$ of diluted ACE2-His to wells labelled 'positive control' and 'test inhibitor'. The plate was incubated at room temperature for $1 \mathrm{~h}$ with slow shaking. The plate was washed three times with $100 \mu \mathrm{l} 1 \mathrm{x}$ Immuno buffer. The wells were blocked by adding $100 \mu \mathrm{l}$ of blocking buffer 2 to each well and incubated for $10 \mathrm{~min}$ at room temperature.

\section{Readout}

Anti-His-HRP was diluted 1000-fold with blocking buffer 2 and $100 \mu \mathrm{l}$ was added to each well and incubated for $1 \mathrm{~h}$ at room temperature with slow shaking. The plate was washed three times with $100 \mu 1$ 1x Immuno Buffer. The wells were blocked by adding $100 \mu$ l of Blocking Buffer 2 to each well and incubated for $10 \mathrm{~min}$ at room temperature. $50 \mu 1$ ELISA ECL Substrate A and $50 \mu 1$ ELISA ECL Substrate B were mixed and then $100 \mu$ added to each well. Chemiluminescence was immediately read. 'Blank' value was subtracted from all readings. At each concentration the test was performed in triplicates and the average of 3 values with their standard deviation was studied.

\section{Results}

The test was performed with serial dilutions of the rose extract, and the chemiluminescence was recorded. Figure 1 shows the SARS-CoV-2 spike and ACE2 inhibition. When the concentration was increased the inhibition was seen. The inhibition of interaction starts at 0.002 percent $\mathrm{v} / \mathrm{v}$ and increases when the concentration is increased. The $50 \%$ inhibitory concentration was 0.75 percent $\mathrm{v} / \mathrm{v}$ with a confidence interval of 0.648 to 0.849 (Table 2 , supplement table 1). When the concentration about 1.8 percent $\mathrm{v} / \mathrm{v}$, the inhibition was near $90 \%$. The control values, which were tested with PBS and normal saline, did not show any changes. 


\section{Discussion}

\section{Inhibition of attachment}

The current study has shown a possible benefit by the rose extract inhibiting the SARS-CoV-2 spike protein:ACE2 interaction in a dose dependent fashion. This can impede the step of the viral replication stage and thereby prevent the attachment of SARS-CoV-2 viruses to the host cell surface before entering the cell. SARS-CoV-2 viruses are capable of active replication in the respiratory tract. Drugs targeting the interaction between the spike protein of SARS- CoV-2, and ACE2 would offer some protection against the viral infection. The clinical benefits of this observation need to be evaluated in patients. Since the mutation rates of coronaviruses are very high (approximately 1 x 10-3)9 especially in the spike protein domain, which can reduce the efficacy of the vaccines, inhibition of spike attachment to ACE2 would be a useful measure. The mutation rate of DNA viruses is 5 orders lower (1x10-8). At present, a dedicated vaccines for Covid-19 are under development worldwide, which could take about $6 \mathrm{~m}$ in clinical evaluation.

\section{Anti-inflammatory effects}

The rose extract has the potentials to inhibit inflammatory cytokines. This unregulated or hyperresponsive inflammatory cascade results in cytokine storm in Covid-19.10 Our bench study with HUVEC cells revealed a significant reduction in the secretion of biomarkers with rose extract. In particular inflammatory mediators secreted by endothelium like IL1, IL2, IL6, TNF R1, TNF alpha, gp130, IFN gamma, ADAMST13 were some of the biomarkers which were reduced.3 The reduction in biomarkers was observed when tested in hypoxic conditions. Late pulmonary fibrosis after recovery is a possible complication in SARS and MERS.11 The exact extend of this sequelae after the infection is not known. Hence, there is a possibility of the rose extract reducing long-term pulmonary fibrosis by inflammation regulation in acute infections. However, this needs to be studied further in-vivo first in animal models.

\section{Bioavailability}

The simplest method of bio-availability or drug delivery is possibly through steam inhalation. Steam inhalation for respiratory tract infections is a commonly used treatment method. A target of 0.75 to 1.5 percent concentration of rose extract in the respiratory tract is achievable. The other method would be a nebulisation using the rose extract. Both these methods have the advantage of being transient exposure to the extract and thereby minimizing systemic absorption. These 
observations need to be tested in animal models and after that in Covid-19 clinical scenarios. In the initial stages, a low concentration can be used, and after that higher concentration could be tested.

\section{Conclusion}

The rose extract has the potentials to inhibit SARS-CoV-2 spike protein to ACE-2 inhibitor interaction in a dose-dependent manner and the IC50 concentration was 0.75 percent v/v. Further studies are required in vivo to evaluate the benefits of this observation.

Conflict of interests: None

Source of funding: None

Ethical considerations: Not applicable

Author contributions: MCA conceived the idea and method, designed the study, analysed the results, and wrote the paper. EM performed the analysis, derived the results and contributed to its details. 
Figure 1. SARS-CoV-2 spike:ACE2 inhibition with increasing concentration of rose extract.

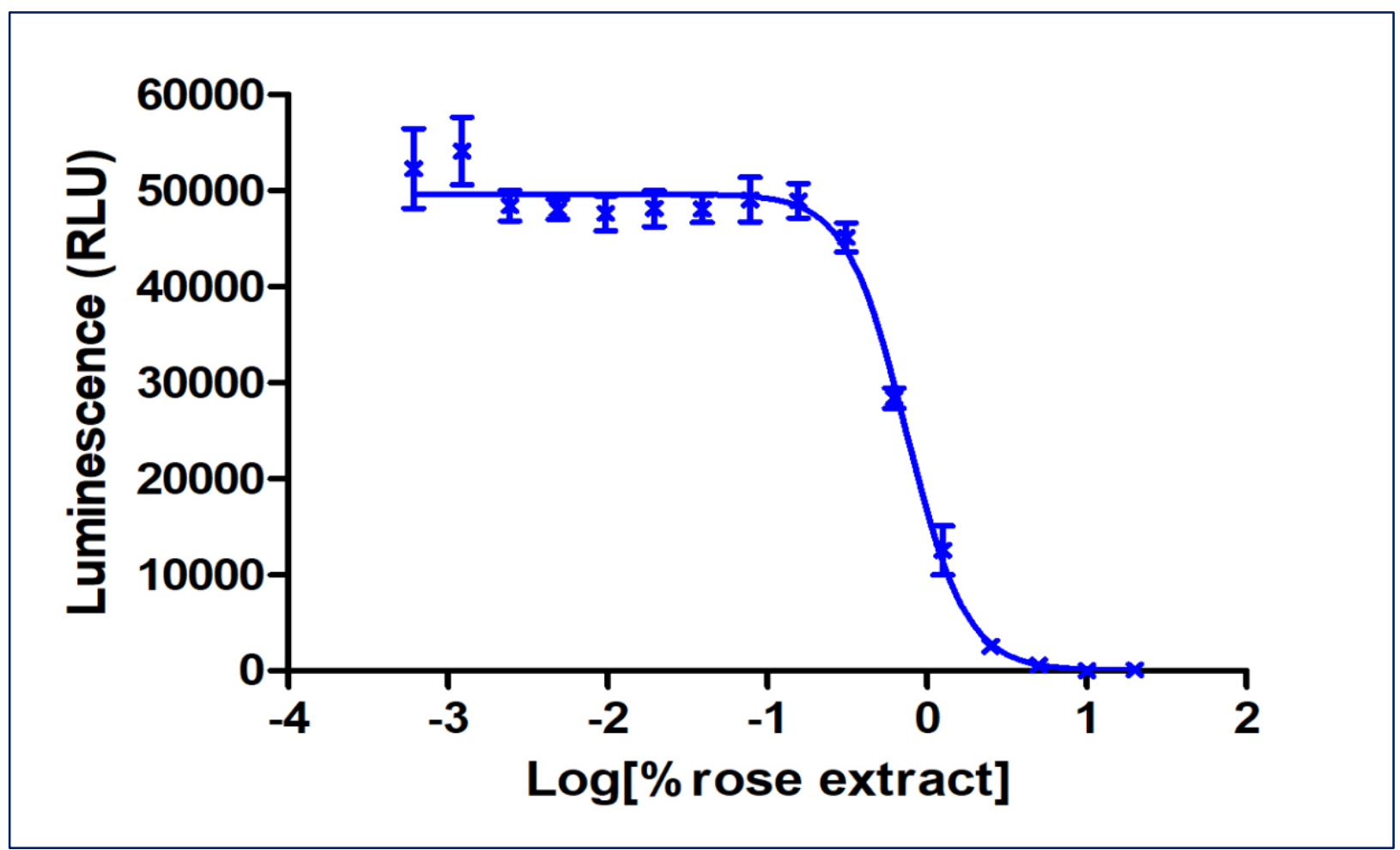


Table 1: Distribution of reagents and compounds.

\begin{tabular}{lccc}
\hline & Blank & Positive control & Test inhibitor \\
\hline $\begin{array}{l}\text { 1xImmuno buffer 1 } \\
\begin{array}{l}\text { Test inhibitor } \\
\text { (compound) }\end{array}\end{array}$ & $40 \mu \mathrm{l}$ & $20 \mu \mathrm{l}$ & $20 \mu \mathrm{l}$ \\
\hline $\begin{array}{l}\text { Inhibitor buffer (for } \\
\text { example, 5\% DMSO in }\end{array}$ & - & - & $10 \mu \mathrm{l}$ \\
water) & $10 \mu \mathrm{l}$ & $10 \mu \mathrm{l}$ & - \\
ACE2-His & - & & \\
\hline Total & $50 \mu \mathrm{l}$ & $20 \mu \mathrm{l}$ & $20 \mu \mathrm{l}$ \\
\hline
\end{tabular}


Table 2: Results of chemiluminescence assay of the test and control wells.

\begin{tabular}{|c|c|c|c|c|c|c|c|c|}
\hline \\
\hline & & \multicolumn{5}{|c|}{ Luminescence (RLU) } & \multicolumn{2}{|c|}{$\begin{array}{l}\text { SARS-CoV-2 } \\
\text { Spike:ACE2 binding } \\
\text { reaction (\% of } \\
\text { positive control) }\end{array}$} \\
\hline & & $\begin{array}{l}\text { Replicate } \\
1\end{array}$ & Replicate 2 & Replicate 3 & Average & $\begin{array}{l}\text { Standard } \\
\text { deviation }\end{array}$ & Average & $\begin{array}{l}\text { Standard } \\
\text { deviation }\end{array}$ \\
\hline \multicolumn{2}{|l|}{ Blank $(\mathrm{H} 2 \mathrm{O})$} & 37 & 26 & 29 & 31 & 6 & $0.06 \%$ & $0.01 \%$ \\
\hline \multicolumn{2}{|l|}{ Blank (PBS) } & 44 & 27 & 25 & 32 & 10 & $0.06 \%$ & $0.02 \%$ \\
\hline \multicolumn{2}{|c|}{ Positive control $(\mathrm{H} 2 \mathrm{O})$} & 51050 & 50177 & 52598 & 51275 & 1226 & $100.00 \%$ & $2.39 \%$ \\
\hline \multicolumn{2}{|c|}{ Positive control (PBS) } & 53322 & 52465 & 52984 & 52924 & 432 & $103.22 \%$ & $0.84 \%$ \\
\hline \multirow{16}{*}{$\begin{array}{l}\text { Rose extract } \\
\text { concentration in } \\
\text { the reaction mix } \\
(\% \mathrm{v} / \mathrm{v})\end{array}$} & 20 & 51 & 59 & 57 & 56 & 4 & $0.11 \%$ & $0.01 \%$ \\
\hline & 10 & 48 & 51 & 39 & 46 & 6 & $0.09 \%$ & $0.01 \%$ \\
\hline & 5 & 391 & 590 & 748 & 576 & 179 & $1.12 \%$ & $0.35 \%$ \\
\hline & 2.5 & 2310 & 2198 & 3091 & 2533 & 486 & $4.94 \%$ & $0.95 \%$ \\
\hline & 1.25 & 10039 & 15163 & 12367 & 12523 & 2566 & $24.42 \%$ & $5.00 \%$ \\
\hline & 0.625 & 28530 & 29335 & 27254 & 28373 & 1049 & $55.33 \%$ & $2.05 \%$ \\
\hline & 0.3125 & 43338 & 45931 & 46054 & 45108 & 1534 & $87.97 \%$ & $2.99 \%$ \\
\hline & 0.1563 & 47801 & 47939 & 51011 & 48917 & 1815 & $95.40 \%$ & $3.54 \%$ \\
\hline & 0.0781 & 48107 & 47337 & 51672 & 49039 & 2313 & $95.64 \%$ & $4.51 \%$ \\
\hline & 0.03906 & 49664 & 47443 & 47062 & 48056 & 1405 & $93.72 \%$ & $2.74 \%$ \\
\hline & 0.01953 & 48896 & 45982 & 49449 & 48109 & 1863 & $93.83 \%$ & $3.63 \%$ \\
\hline & 0.00977 & 49235 & 45597 & 47970 & 47601 & 1847 & $92.83 \%$ & $3.60 \%$ \\
\hline & 0.00488 & 48096 & 46929 & 49035 & 48020 & 1055 & $93.65 \%$ & $2.06 \%$ \\
\hline & 0.002441 & 49202 & 49530 & 46605 & 48446 & 1602 & $94.48 \%$ & $3.13 \%$ \\
\hline & 0.001221 & 57515 & 50490 & 54284 & 54096 & 3516 & $105.50 \%$ & $6.86 \%$ \\
\hline & 0.000610 & 56507 & 52135 & 48170 & 52271 & 4170 & $101.94 \%$ & $8.13 \%$ \\
\hline
\end{tabular}




\section{Bibliography}

1. Cao, W., Li, T. COVID-19: towards understanding of pathogenesis. Cell Res 30, 367-369 (2020). https://doi.org/10.1038/s41422-020-0327-4

2. Lurie N, Saville M, Hatchett R, Halton J. Developing Covid-19 Vaccines at Pandemic Speed. New England Journal of Medicine. 2020;382(21):1969-1973.

3. Phelan J, Deelder W, Ward D, Campino S, Hibberd M, Clark T. Controlling the SARS-CoV-2 outbreak, insights from large scale whole genome sequences generated across the world. 2020; doi.org/10.1101/2020.04.28.066977

4. Arokiaraj MC, Menesson E. Novel anti-inflammatory and immunomodulation effects of Rose on the endothelium in normal and hypoxic invitro conditions. Angiologia e Cirurgia Vascular. 2019;15(4):238-248.

5. Ackermann M, Verleden S, Kuehnel M, Haverich A, Welte T, Laenger F et al. Pulmonary Vascular Endothelialitis, Thrombosis, and Angiogenesis in Covid-19. New England Journal of Medicine. 2020;DOI:10.1056/NEJMoa2015432.

6. Hariri L, Hardin C. Covid-19, Angiogenesis, and ARDS Endotypes. New England Journal of Medicine. 2020; DOI: 10.1056/NEJMe2018629

7. Hoffmann M, Kleine-Weber H, Schroeder S, Krüger N, Herrler T, Erichsen S et al. SARS-CoV-2 Cell Entry Depends on ACE2 and TMPRSS2 and Is Blocked by a Clinically Proven Protease Inhibitor. Cell. 2020;181(2):271-280.e8.

8. Yan R, Zhang Y, Li Y, Xia L, Guo Y, Zhou Q. Structural basis for the recognition of SARS-CoV2 by full-length human ACE2. Science. 2020;367(6485):1444-1448.

9. Carrasco-Hernandez R, Jácome R, López Vidal Y, Ponce de León S. Are RNA Viruses Candidate Agents for the Next Global Pandemic? A Review. ILAR Journal. 2017;58(3):343-358.

10. Coperchini F, Chiovato L, Croce L, Magri F, Rotondi M. The cytokine storm in COVID-19: An overview of the involvement of the chemokine/chemokine-receptor system. Cytokine \& Growth Factor Reviews. 2020; doi.org/10.1016/j.cytogfr.2020.05.003

11. George P, Wells A, Jenkins R. Pulmonary fibrosis and COVID-19: the potential role for antifibrotic therapy. The Lancet Respiratory Medicine. 2020; doi: 10.1016/S22132600(20)30225-3. 


\section{Supplement}

\section{Feature of dose response curve}

$\log ($ inhibitor) vs. response - Variable slope Value

$\begin{array}{ll}\text { Best-fit values } & \\ \text { IC50 } & 0.742 \\ \text { E max } & 49603\end{array}$

Std. Error

$\begin{array}{ll}\text { IC50 } & 1.063 \\ \text { Span } & 1356 \\ \text { 95\% confidence intervals } & \\ \text { IC50 } & 0.648 \text { to } 0.849 \\ \text { Span } & 46649 \text { to } 52558 \\ \text { R square } & 0.99\end{array}$

